\title{
AUV Based Multi-vehicle Collaboration: Salinity Studies in Mar Menor Coastal Lagoon
}

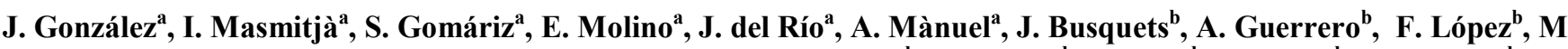

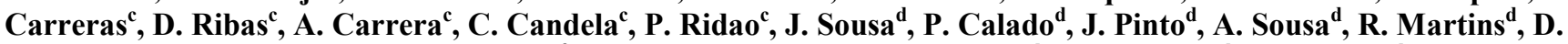

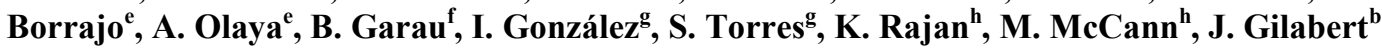

\begin{abstract}
${ }^{a}$ SARTI Research Group, Electronics Department, Universitat Politécnica de Catalunya. ${ }^{b}$ Universidad Politécnica de Cartagena. ${ }^{c}$ Universitat de Girona. ${ }^{d}$ LSTS, Universidade do Porto. ${ }^{e}$ Universidad Carlos III. ${ }^{f}$ SOCIB. ${ }^{g}$ CETMAR, Vigo.

${ }^{h}$ MBARI, California.
\end{abstract}

\begin{abstract}
An experiment with different AUVs was carried out in the Mar Menor Coastal Lagoon from October 31 to November 5 in order to measure and assess the influence of the water from the Mar Menor on the adjacent area of the Mediterranean. This was carried out as a result of the meeting held between several institutions from the Iberian Peninsula and EEUU (see Vilanova Marine Science/Robotics Meeting 2010). The experiment was to launch several AUVs at the same time in different zones of the Mediterranean and Mar Menor lagoon. AUVs took salinity data trying to do a coordinated mission during two operative days (November 3 and November 5). Others days of the experiment were used to the vehicle's preparation and error correction (November 2 and November 4). This paper presents the steps followed in preparation and operative days with the set of AUVs. This paper presents also the salinity results obtained during these missions.
\end{abstract}

Keywords: Autonomous underwater vehicles, data acquisition, marine systems, trajectory planning, electronic applications.

\section{INTRODUCTION}

The Mar Menor is a large coastal lagoon in the Iberian Peninsula and one of the largest in Europe. It is an emblematic wetland on the RAMSAR sites list for conservation providing a large quantity of goods and services to the society. Many interests from tourism to fisheries to intense agriculture in the watershed to conservation overlap the area. The economic value of fisheries, for instance, is substantially higher in the lagoon than outside.

A major program to monitor the lagoon is being funded by the Regional Government of Murcia as a strategic project in the Science and Technology Regional Plan. The "Campus Mare Nostrum", a joint venture of the Technical University of Cartagena and University of Murcia, has been awarded as Campus of Excellence in the Spanish University System. This campus has the marine science and technology as one of the major challenge themes. Although the lagoon is important in itself, the SE coast of Spain is an area of large coastal oceanographic interest as shown in Fig. 1.

The Mar Menor lagoon is located in a semiarid region of Spain with evaporation exceeding precipitation and runoff thus providing its hyper saline character (45-47 PSU) and a range of temperature spanning from $10^{\circ} \mathrm{C}$ to $32^{\circ} \mathrm{C}$ seasonally. It has $135 \mathrm{~km} 2$ with $22 \mathrm{~km}$ long (maximum distance) and 12 $\mathrm{km}$ maximum wide with a maximum depth of $6 \mathrm{~m}$ and average of $3.5 \mathrm{~m}$. With a volume of about $5.8 \times 108 \mathrm{~m}^{3}$, its water renewal time is of 423 days (1.16 years approximately, see Gilabert 2009). The lagoon is separated from the
Mediterranean Sea by a sand bar called La Manga. The exchange of water between the Lagoon and the adjacent Mediterranean Sea is carried out by three inlets (see Fig. 2).

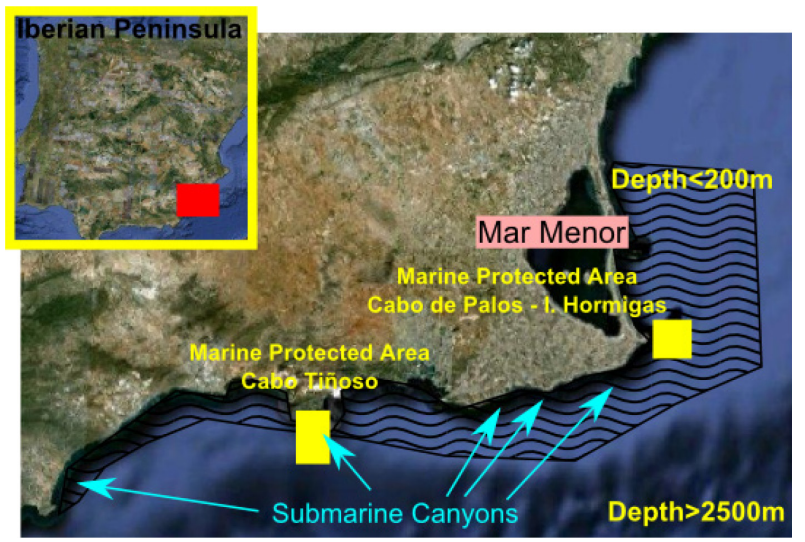

Fig. 1. Location of the Mar Menor lagoon and oceanographic singularities of the area.

In order to understand the capacity of the lagoon as a biological buffer it is critical to understand the exchange of water between the Mediterranean Sea and the lagoon. Many species are not allowed to enter into the lagoon because of the strong environmental gradient, mainly imposed by salinity; but others, already adapted to the much more stressed lagoon environment, do leave the lagoon thus providing more resistant populations to changing environmental factors in the Mediterranean (e.g. by global warming trends). The lagoon 
is, from this point of view, seen as a natural laboratory to understand future changes in larger water masses. The stressed environment is also genetically selecting the species thus providing a reserve of biodiversity. Lagoon water going out to the Mediterranean Sea is, by itself, an important vector of exportation of selected species to the Mediterranean Sea.

Validation of a 3D model of the saltier water tongue requires in situ simultaneous measurements in the area of influence in the three dimensions with the best available technology. AUVs are by now the most advanced technology available to this kind of measurements and can account for both spatial and temporal variations of water mass given their mobility. They are also cost-effective and adaptable to the changing environment in ways that traditional ship-based observations cannot.
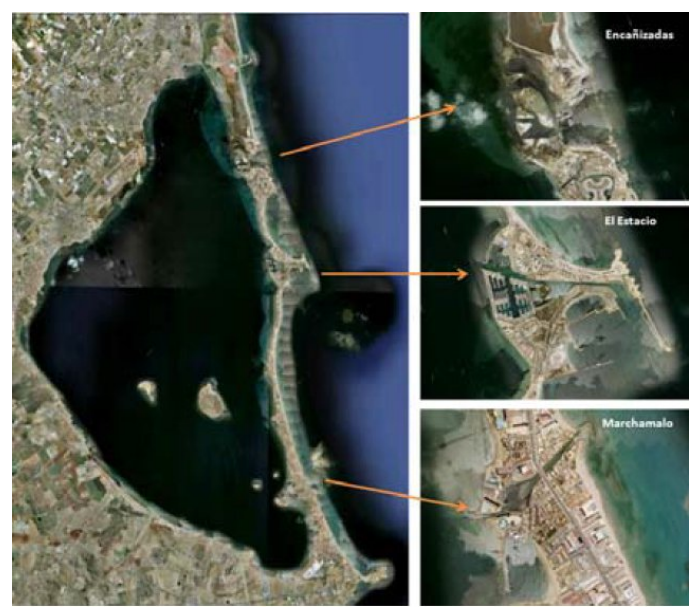

Fig. 2. Inlets of the Mar Menor Lagoon. North: The Encañizadas; Middle: The Estacio channel; South: Marchamalo inlet.

\section{PARTICIPATING INSTITUTIONS}

The main scientific goal of the experiment is to determine the extent of the saltier tongue of water going out of the lagoon through The Estacio channel towards the Mediterranean Sea (Gilabert et al. 2011). In order to achieve this goal, several institutions were involved in the experiment, some of them with AUVs and others bringing support to the operations. Following there are the participating institutions:

- Technical University of Cartagena

- University of Girona

- $\quad$ SARTI Group, Technical University of Catalonia

- LSTS, University of Porto

- $\quad$ PLG Group, Charles III University

- $\quad$ SOCIB

- CETMAR, Vigo

- MBARI, California

\subsection{SARTI Group - Universitat Politècnica de Catalunya}

SARTI Group is a research institute in Vilanova i La Geltrú (Spain) from the Universitat Politècnica de Catalunya. One of its projects is the developing of an AUV called Guanay II and this was one of the vehicles that participated in the experiment.

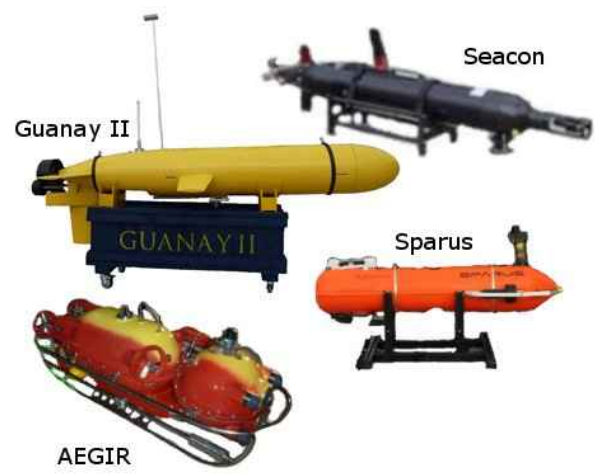

Fig. 3. Vehicles which participated in the experiment. Seacon from UP. Sparus from UDG. Guanay II from UPC. AEGIR from UPCT.

The Guanay II has been designed to navigate over shallow water. Its principle's movement is to navigate over the surface and realize vertical immersions to take measurements of the water column (Gomáriz et al. 2011). The vehicle is torpedo-shaped and weighs $90 \mathrm{~kg}$. Its dimensions are 2.36 in length by 0.32 in diameter.

\subsection{Underwater vehicles lab-Universidad Politécnica de Cartagena}

The UPCT Underwater Vehicles Lab is a multidisciplinary research group with experts in biological oceanography, naval architecture, Oceanic Engineering, robotics, artificial neural networks, electronics and ITs. The goal of this team is the development of equipment useful for oceanographic exploration. This lab has been constituted during 2010, and in this moment disposes several granted projects for Mar Menor exploration and underwater vehicles design. One of the research lines in the field of artificial intelligence is the application of neural networks biologically inspired to the control and trajectory generation. Another important research line is the design of marine vehicles for oceanographic exploration. The lab has an underwater vehicle remotely operated for mine searching (donated by the Spanish Army which is being remodelled, see Guerrero et al. 2011) and a towed vehicle with an 8 meter vessel for operations.

\subsection{LSTS - Faculdade de Engenharia da Universidade do Porto}

The "Laboratório de Sistemas e Tecnologias Subaquáticas" (LSTS) is a research unit in Porto (Portugal) from the Faculdade de Engenharia da Universidade do Porto, that started operations with AUVs in 1997. Since then, LSTS designed and developed:

- ROVs for underwater structure inspection

- low cost AUVs (such as Seacon, see Sousa et al. 2009) for coastal oceanography 
- Unmanned Air Vehicles (UAV) that will work as a sensor platform

- low cost sensor modules for remote environmental data collection

- acoustic navigation for multiple AUVs

- operational concepts for the coordinated operation of multiple AUVs

- control architecture for the coordination and control of multiple vehicles.

To further improve the development process of AUVs and UAVs, joint programs were started with the Portuguese Air Force and the Portuguese Navy.

Over the past few years, LSTS also devoted an intense effort to the development of feasible concepts for the networked operation of multiple vehicles and systems.Today USTL aggregates over 20 researchers including Faculty, Ph.D. and M.Sc. students, and full-time engineers.

\subsection{Universitat de Girona}

The team from the University of Girona (Spain) is part of the Underwater Robotics Research Centre (http://cirs.udg.edu). The vehicle that was used for these experiments was the Sparus AUV (Mallios et al. 2011). Sparus is a $35 \mathrm{Kg}, 50$ meters depth torpedo shaped vehicle of $1.22 \mathrm{~m}$ length $\mathrm{x} 0.23 \mathrm{~m}$ diameter with hovering capabilities. Its motion is controlled by three Seabotix thrusters and two fins, which allow the control of 4 degrees of freedom (surge, heave, pitch and way). The vehicle can be controlled as a flying AUV or as hovering ROV. Among its sensor suit, for navigation purposes, the robot has a MTi Motion Reference Unit (MRU) from XSens Technologies, a pressure gauge, a Doppler Velocity Log (DVL) from LinkQuest which also includes a compass/tilt sensor and a GPS. For perceiving the environment, the robot has a Micron Mechanical Scan Imaging Sonar (MSIS) from Tritech, 2 video cameras, an echosound and 2 hydrophones. For the experiments presented in this paper, a Seabird Glider Payload CTD was integrated. All devices are controlled with an embedded computer and powered with Li-Ion Batteries that give 3 hours of autonomy at $1 \mathrm{~m} / \mathrm{s}$ of surge speed.

\subsection{MBARI - Monterey Bay Aquarium Research Institute}

The Monterey Bay Aquarium Research Institute (MBARI) was founded in 1987 as a private, non-profit research center funded by the David and Lucile Packard Foundation and is located in Moss Landing, California on the Monterey Bay, one of the most biologically diverse bodies of waters in the world. The institute owns three sea going ships, Remotely Operated Vehicles, Autonomous Underwater Vehicles, a test tank and a number of ocean observing platforms as well as various equipment for scientific analysis in the various labs. MBARI scientists have ocean-going experience and have pioneered a large number of scientific and engineering techniques to better observe, sample and characterize the ocean.
MBARI's contribution to this experiment was the expertise in running inter-disciplinary field experiments for the CANON (www.mbari.org/canon/) program. Further an initial attempt was made to deploy the Oceanographic Decision Support System (ODSS) a shore-based web-enabled software to provide situational assessment, visualization, experiment design, planning and data analysis (Das et al. 2011). The ODSS has been fielded repeatedly for multiple near-shore experiments in the Monterey Bay, California. Our use for AUV2011 however was mixed. With the software hosted in California, poor network latencies and system performance came in the way of the execution of tasks for this field trial. On a quick assessment on site, it was decided to provide a simple map overlay using Google Toolkit on a web browser on a fast server. Expertise of MBARI personnel was further leveraged in data analysis using the substantial backend needed for the ODSS.

\section{$2.6 S O C I B$}

SOCIB (Sistema de Observación Costero de la Islas Baleares, Coastal Observing System of the Balearic Islands) is a multiplatform distributed and integrated system that will provide streams of oceanographic data and modeling services to support operational oceanography in a European and international framework.

One of the main objectives of SOCIB is the study of the physical mechanisms and underlying processes that can explain the dynamics of the coastal ocean system and its interactions with the near-shore and the open ocean.

\subsection{PLG Group - Universidad Carlos III}

UC3M participated in the experiment through its Planning and Learning Group (PLG). PLG is composed of 18 full-time researchers with professional and research experience on the fields of Artificial Intelligence automated planning, machine learning, and problem solving. Its members include $11 \mathrm{PhD}$, and $7 \mathrm{PhD}$ students. The group research focuses on problem solving, especially search and planning techniques, and machine learning applied to problem solving. Recently, some of its members have been integrating deliberative planning techniques with machine learning and execution into robotics platforms in the context of collaborations with the groups of Manuela Veloso (CMU, USA), and Kanna Rajan (MBARI, USA).

\subsection{CETMAR}

The "Centro Tecnológico del Mar-Fundación CETMAR" was funded in 2001 with the initiative of the "Xunta de Galicia" and the "Ministerio de Ciencia e Innovación". Its main objective is to promote cooperation between institutions, research centres and the marine-fishing sector, identifying the needs of the community and helping with the transfer of technology to meet those needs. PROTECMA initiative (Coastal and Marine Environment Protection Technological Platform), which has supported part of these 
event, is an example of CETMAR promotion work. The Marine Technologies Unit (UTMAR) is part of CETMAR and it was created in 2009 in a context of an increasing need of continuous monitoring of the water quality (European Water (2000) and Marine Strategic (2008) Framework Directives). UTMAR contribute to the design and develop of low-cost and open-solution systems for in-situ monitoring of Marine Environment (Oceanographic Buoys and AUVs). In addition, UTMAR has an Oceanographic Calibration Laboratory for temperature, conductivity, pressure and oxygen oceanographic sensors. This Laboratory is equipped with the best available technology and designed to comply with all the requirements of the current international quality standards.

\section{PREPARATION}

Before operations commenced the different groups performed a series of tasks to prepare their vehicles for deployment. A public relations event was also held to introduce the experiment to the scientific community (see Workshop of Autonomous Underwater Vehicles 2011).

The first challenge of UPorto team was to ensure its $3 \mathrm{G}$ communicator was able to operate in Spain and have access to SMS. In the event of an emergency, the vehicle's controller would then be able to send an SMS message home giving its Latitude/Longitude for geo location.

The UPCT team meanwhile was busy from very early in the day deploying a buoy north of the operating area to seed the French branch of ROMS (Regional Ocean Modeling System) called ROMS-Agrif. The purpose of the couple buoy-model system was to enable real time estimates of the saline plume. This information could be accessed through a webpage and helped in planning the deployment of each day. The team also returned with some Mediterranean water for CTD calibration. Others meanwhile worked at the CAR dock (dock of the Cartagena High Altitude Training Centre) dock to ensure their launch \& recovery system for the AEGIR AUV was working by practicing small boat deployment.

Others helped to deploy markers for testing the small AUVs from Porto even as a steady stream of visitors came by curious to see what the fuss was all about with these funny looking vehicles.

Regarding SARTI Group, first it was revised the LARS (Launch And Recovery System) of the Sorell ship in order to anchor the Guanay II to it. Once this was realized, the Guanay II ballast system was balanced in order to adapt it to the salinity of the sea. Finally, it was realized a small test of navigation with Guanay II near the port.

The Girona team performed several tests to check the navigation performance and the controller for way-point following. Also, the team made the necessary software to convert the CTD measures to salinity measures and to plot them together with the navigation data.

\section{OPERATIONS}

The operations in the Meditarrean and Mar Menor lagoon were scheduled for several days but it was only possible to sail two days altogether due problems with weather conditions (see Mar Menor AUV 2011 Experiment).

\subsection{First day (Nov 3 2011)}

At first day, the weather forecast called for choppy seas with light rain. It was decided that both the Porto and Girona teams would head out to the survey area in the Mediterranean while the UPCT and Vilanova teams would stay inside the lagoon.

Logistically, the previous night it was decided to assign these ships:

- Farallon: U. Girona/Sparus

- Arrecife: U. Porto/Seacon (2)

- Sorell: UPCT/AEGIR \& UPC/Guanay II + 1 RHIB

- 1 backup RHIB and divers on standby at Puerto Maestre

Each of boats had a SPOT tracker in lieu of an AIS marker, so their tracks could be visualized on MBARI's ODSS system.

First out at sea on the fast Arrecife was the UPorto team with the 2 Seacons (one as backup). Following them was the U. Girona group with the Sparus. The latter deployed just off the harbor mouth while the Porto team went further south. The UPCT and Vilanova teams meanwhile split between the Sorell and the accompanying RHIB once Guanay II was deployed. With that deployment, the Sorell with the AEGIR (two body system) headed further south to deploy.

The AEGIR AUV could not measure salinity data due to technical problems. The others AUV could take the data during their missions.

\subsection{Second day (Nov 5 2011)}

The second day was a day with better weather conditions, where it did not rain. The assignment of the ships for each group was the same as the first day, except that UPCT did not sail due technical problems with AEGIR AUV.

Since weather conditions were better, both U. Porto group (Seacon AUV) or U. Girona (Sparus AUV) group and UPC group (Guanay II AUV) sailed to Mediterranean sea in the morning. UPC Group had technical problems taking data, but the other two groups recorded salinity data without major complications.

\subsection{Data management following the deployments}

The data collected by the vehicles were converted to CFNetCDF format hosted on a THREDDS server then loaded into a STOQS database for simplified analysis of the data from all of the platforms. 


\section{RESULTS}

This experiment leads to take measures of salinity in several areas of both Mar Menor and Mediterranean Sea. Following there is the salinity data using Seacon AUV, Guanay II AUV and Sparus AUV.

Fig. 4 shows a 2D measure of salinity using Seacon AUV (U. Porto) near to port Los Narejos in the Mar Menor, where salinity ranged from 41.87 psu to 41.95 psu. Fig. 5 shows other measures with the same Seacon AUV, but in this case in the Mediterranean Sea. The salinity ranged from $37.54 \mathrm{psu}$ to $37.59 \mathrm{psu}$.

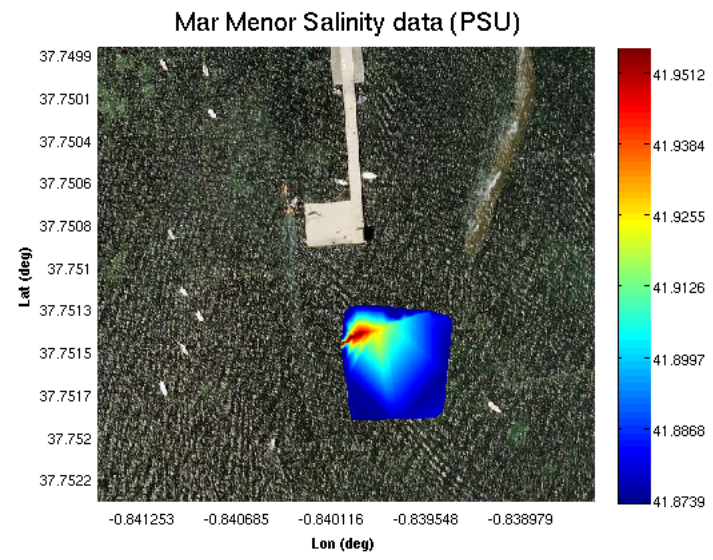

Fig. 4. Seacon AUV: Salinity in Mar Menor.

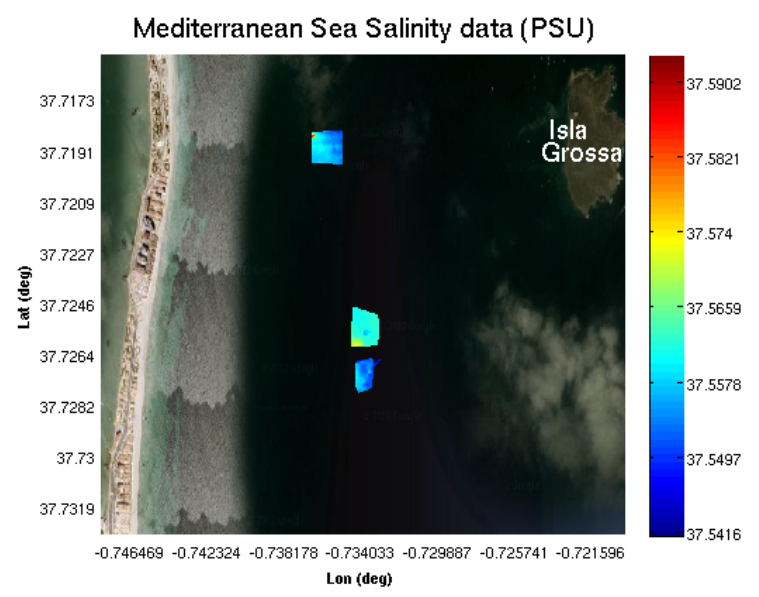

Fig 5. Seacon AUV: Salinity in Mediterranean Sea.

Guanay II AUV (UPC Group) could sail the first day of operations and to sail also in Puerto Maestre taking salinity data. Figs. 6 and 7 show the results obtained in the change in salinity between the two seas. At path made in Mar Menor (path 1) the salinity ranged from 46.59 psu to 43.88 psu as it approached the Puerto Maestre. On the other hand, at path done in Estacio channel (path 2) the salinity ranged from $39.34 \mathrm{psu}$ to $40.87 \mathrm{psu}$. It is noteworthy that the arrival point in the path 1 coincides with the starting point of the path 2 , where they noticed a decrease in salinity of about $4.54 \mathrm{psu}$ from day to day. Thus, the results show important data to study the plume of salinity. The results also show that between the Mar Menor and the Mediterranean salinity there was differences of up to $7.5 \mathrm{psu}$.

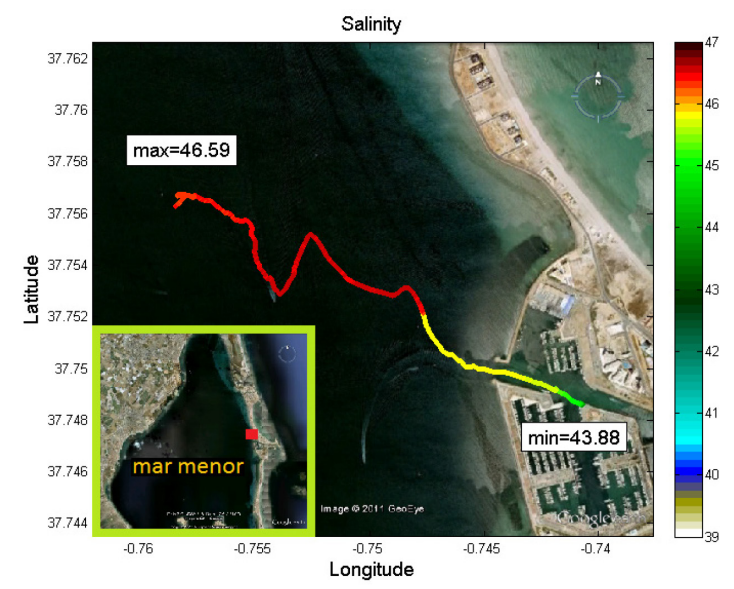

Fig. 6. Guanay II AUV: Salinity in Mar Menor (path 1).

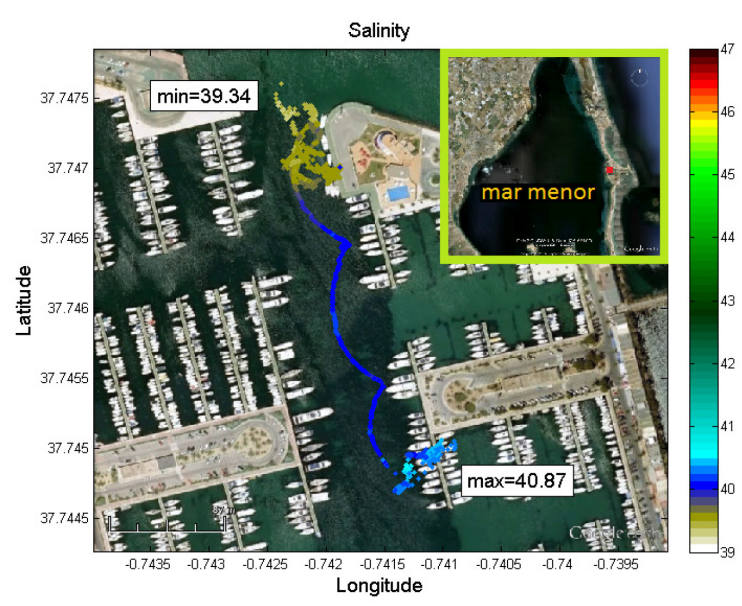

Fig. 7. Guanay II AUV: Salinity in Puerto Maestre (path 2).

Sparus AUV was able to navigate in the Mediterranean sea, just in front of Puerto Maestre, during the first and second day of operations. During the first day, the experiments were used to test all the systems and to store CTD values. Two 100 $\mathrm{m}$ transects were done from which the maximum measured salinity was 37.8 psu. The vehicle navigated between 2 and 5 meters. During the second day, a long trajectory of 1.300 meters was done in front of Puertro Maestre (see Fig. 8). Since the plume was assumed to be at a very close distance to the sea bottom, the vehicle was programmed to perform vertical profiles every 50 meters. In every vertical profile, the vehicle submerged from 4 meters (transit depth) till 1.5 meters altitude, thus approaching safely to the sea bottom to detect the plume. Therefore, Sparus was combining torpedolike motion, for way-point reaching at constant 4 meters depth, with hovering motion, for vertical profiling. The vehicle detected a maximum salinity value of $38.8 \mathrm{psu}$, which was due to the plume. Figure 9 shows a detail of this trajectory, in which one of the vertical profiles can be observed. 


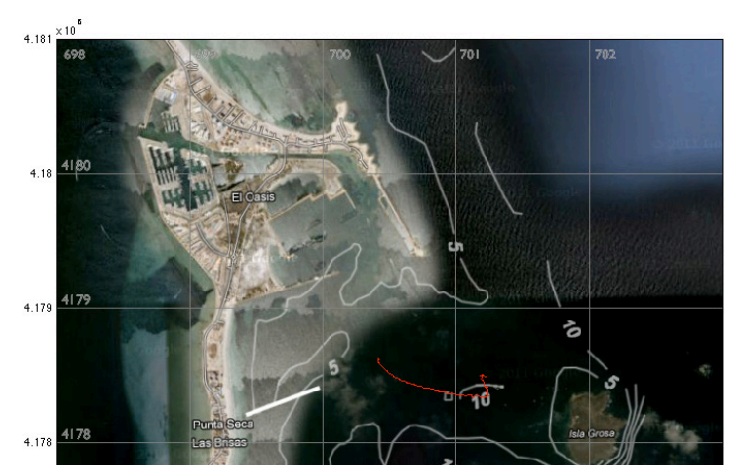

Fig. 8. Sparus AUV: Final trajectory in red.

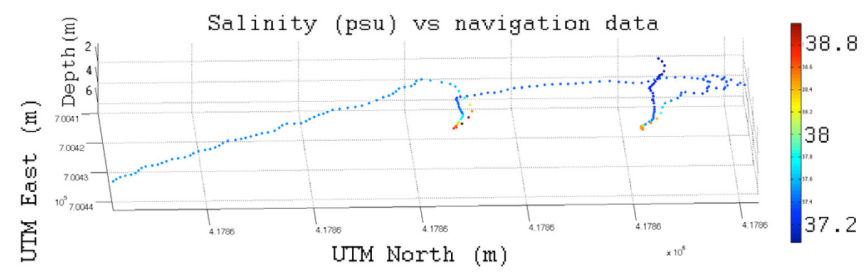

Fig. 9. Sparus AUV: detail of vertical profile with a salinity colored line.

\section{DISCUSIONS AND CONCLUSIONS}

This experiment has served as a first team collaboration between several institutions which are involved in the development of marine technologies as autonomous underwater vehicles (AUVs). This integration help to each research institute to improve their knowledge in all areas. However, there are different issues to consider in the accomplishment of the experiment.

The experiment timelines were small (four days in preparation and operations) thus it is a short time to get a well data of salinity and to face the different issues that may occur during the experiment, as bad weather conditions. In certain aspects, some individual goals were not entirely clear to the other groups and this provoked some setbacks, so that the mission could have been done in a more synchronized and effective. Despite all these challenges, the data obtained during this experiment has substantial value tied both to the social needs of the local community and to the scientific needs for better predictive capabilities.

\section{ACKNOWLEDGMENT}

- The project Guanay (SARTI Group) has been funded by the Spanish Ministry of Education and Science and the European Union (FEDER), project $\mathrm{n}^{\circ}$ : CTM2010-16274 and project $n^{\circ}$ : CTM2009-08867.

- The University of Girona team participated in this campaign thanks to projects: Spanish government (RAUVI DPI2008-06545-C03-03 and TRITON - DPI2011-27977C03-02); FP7 European Union (TRIDENT - ICT-248497).

- The research leading to these results has received funding from the European Commission FP7-ICT Cognitive Systems, Interaction, and Robotics under the contract \#270180
(NOPTILUS), and from the project Persist by Fundação para a Ciência e a Tecnologia (FCT).

- Coastal Monitoring System for the Mar Menor Coastal Lagoon, Regional Government of Murcia, Spain, (PEPLAN 463.02-08 CLUSTER).

- The Technological Platform "PROTECMA" (Plataforma Tecnológica Para La Proteccion De La Costa Y Del Medio Marino) has been funded by the Innovation and Science Spanish Ministry, now economy and competitiveness Ministry, through the subprogram Technological Platforms (INNFLUYE), project $n^{\circ}$ : RET-310000-2010-2.

- All the sponsors and institutions that kindly collaborated with the infrastructure and facilities set available for the experiment.

\section{REFERENCES}

Das, J.; Maughan, T.; McCann, M; Godin, M; O’Reilly, T.; Messie, M; Bahr, F.; Gomes, K.; Py, F.; Bellingham, J.; Sukhatme, G.; and Rajan, K. (2011) "Towards mixedinitiative, multi-robot field experiments: Design, deployment, and lessons learned," in Proc. Intelligent Robots and Systems (IROS). California.

Gilabert, J. (2009). "Modelado hidrodinámico y de ecosistemas en el Mar Menor: una herramienta para su conservación y restauración". Instituto Euromediterráneo del Agua (Ed.). El Mar Menor. Estado actual del conocimiento científico. pp.:497-516.

Gilabert, J.; Gomáriz, S.; Molino, E.; del Río, J.; Mànuel, A.; Carreras, M.; Ridau, P.; Sousa, J.; Martins, R.; Borrajo, D.; Olaya, A.; Garau, B.; González, I.; Busquets, J. (2011). "AUV-2011 underwater robotics experiment in the mar menor coastal lagoon", Instrument Viewpoint $\mathrm{n}^{\circ} 11$, pags. $88-90$.

Gomáriz, S.; González, J.; Arbos, A.; Masmitja, I.; Masmitja, G.; Prat, J.(2011). "Design and construction of the GUANAY-II autonomous underwater vehicle" OCEANS, 2011 IEEE - Spain.

Guerrero, A.; García, F.; Gilabert, J. (2011) “A biologically inspired neural network for Navigation with Obstacle avoidance in Autonomous Underwater and Surface Vehicles" Oceans 2011.

Mallios, A.; Ridao, P.; Carreras, M.; Hernandez, E. (2011) "Navigating and mapping with the SPARUS AUV in a natural and unstructured underwater environment," OCEANS 2011 , pp.1-7.

Mar Menor AUV 2011 Experiment. https://sites.google.com/ site/auvexperiment2011/. (last accesed: 03/02/2012)

Sousa, J.; Carvalho, C. (2009); "The SeaCon AUV system: technology evaluation, training and development of concepts of operation for the Portuguese Navy". in Proc. Maritime systems and technology conference. Stockholm, Suecia.

Vilanova Marine Science/Robotics Meeting. Nov 15th 2010. http://sites2.upc.edu/ www-sarti/web/cat/meeting /meeting.php . (last accessed: 03/02/2012).

Workshop of Autonomous Underwater Vehicles: new technological advances. Exercise "AUV 2011". http://www.ptprotecma.es/protecma/ index.php?option $=$ com_content\&task $=\quad$ view\&id $=898$ (last accesed: 03/02/2012) 